\title{
Estudio de caso: Evaluación y efecto del alimento con oxitetraciclina preparado industrialmente y con un procedimiento establecido en granja sobre el desarrollo del camarón Penaeus vannamei y su acumulación en músculo y hepatopáncreas
}

\author{
Sergio Gámez-Bayardo ${ }^{1}$, Angelica Espinosa-Plascencia ${ }^{1}$, Maribel Jiménez-Edeza ${ }^{2}$, \\ Adolfo Pérez-Álvarez ${ }^{3}$, Alfonso García-Galaz ${ }^{1}$ y María del Carmen Bermúdez-Almada ${ }^{1 *}$ \\ ${ }^{1}$ Centro de Investigación en Alimentación y Desarrollo, A.C. (CIAD, A.C.). Coordinación de Ciencia de los \\ Alimentos, Laboratorio de Análisis Biológicos. Carretera Gustavo Enrique Astiazarán Rosas \# 46, Col. La Victoria, \\ Hermosillo 83304 Sonora, México. ${ }^{2}$ Universidad Autónoma de Sinaloa, Laboratorio de Investigación y \\ Diagnóstico Microbiológico, Facultad de Ciencias Químico Biológicas. Culiacán 80013, Sinaloa. \\ ${ }^{3}$ Granja Acuícola Maricultura del Pacífico. Hermosillo 83240, Sonora, México. E-mail: *cbermudez@ciad.mx
}

\begin{abstract}
RESUMEN
La investigación consistió en comparar dos métodos de adición de oxitetraciclina (OTC) en el alimento para camarón, así como el efecto en su desarrollo y en la acumulación en músculo y hepatopáncreas de Penaeus vannamei. Se realizó un bioensayo durante 30 días empleando 180 camarones juveniles utilizando dos formulaciones para alimentarlos con (OTC-1 y OTC-2). Los alimentos medicados se administraron durante 14 días, posteriormente se les dio alimento sin antibiótico por 16 días más, y se determinó la calidad fisicoquímica del agua. En los camarones se evaluó lo siguiente: parámetros biológicos y fisiológicos, acumulación $\left(\mathrm{C}_{\text {máx }}\right)$ de OTC y tiempo de eliminación en el músculo y hepatopáncreas determinada por cromatografía líquida de alta resolución (HPLC). El desarrollo de los organismos mostró una sobrevivencia de 99.72\% para OTC-1 y 100\% para OTC-2. La $C_{\text {máx }}$ de OTC en el músculo del grupo OTC-1 fue de $16.09 \pm 1.80 \mu \mathrm{gg}^{-1} \mathrm{y}$ en el de OTC-2, $6.62 \pm 0.87 \mu \mathrm{gg}^{-1}$; en el hepatopáncreas fue de $105.85 \pm 17.56 \mu \mathrm{gg}^{-1}$ con (OTC-1) y $79.16 \pm 15.61 \mu \mathrm{gg}^{-1}$ con (OTC-2), encontrando una asociación en la $\mathrm{C}_{\text {máx }}$ de OTC respecto al método de adición $(\mathrm{p} \leq 0.05)$. El alimento medicado mediante un proceso industrial con $(\mathrm{OTC}-1)$ y el adicionado con OTC en granja (OTC-2) requieren mayor control de calidad para asegurar la concentración del antibiótico deseada, antes de su administración en los cultivos de camarón.
\end{abstract}

Palabras clave: oxitetraciclina, Penaeus vannamei, acumulación, parámetros biológicos.

Case study: Evaluation and effect of feed with oxytetracycline industrially prepared and with a farm-based procedure on the development of Penaeus vannamei shrimp and its accumulation in muscle and hepatopancreas

\begin{abstract}
This research consisted of comparing two methods of adding oxytetracycline (OTC) in shrimp feed, as well as its development and its accumulation in muscle and hepatopancreas from Penaeus vannamei. A bioassay was carried out for 30 days using 180 juvenile shrimp testing two formulations to feed the organisms (OTC-1 and OTC-2). The formulations medicated were administered 14 days, and subsequently they were fed with a diet without antibiotic for 16 more days and water quality was determinate by physicochemical data. In shrimps the following was evaluated: Biological and physiological parameters, accumulation $\left(\mathrm{C}_{\text {max }}\right)$ of OTC and elimination time in muscle and hepatopancreas were determined by high performance liquid chromatography (HPLC). The development of organisms showed a survival of $99.72 \%$ for OTC-1 and $100 \%$ for OTC-2. The $\mathrm{C}_{\text {máx }}$ of OTC in muscle for the OTC-1 group was $16.09 \pm 1.80 \mu \mathrm{gg}^{-1}$ and the OTC-2 group was $6.62 \pm 0.87 \mu \mathrm{gg}^{-1}$; in the hepatopancreas it was $105.85 \pm 17.56$ with $(\mathrm{OTC}-1)$ and $79.16 \pm 15.61 \mu \mathrm{gg}-1$ with (OTC-2) finding an association of $\mathrm{C}_{\text {máx }}$ of OTC by the method of addition $(\mathrm{p} \leq 0.05)$. The medicated shrimp feed through an industrial process $(\mathrm{OTC}-1)$ and the addition on the farm (OTC-2) require greater quality control to ensure the desired concentration of the antibiotic, before its administration in shrimp cultures.
\end{abstract}

Keywords: oxytetracycline, Penaeus vannamei, accumulation, biological parameters.

Artículo recibido el 16 de julio del 2020.

Artículo aceptado el 23 de marzo del 2021. 


\section{INTRODUCCIÓN}

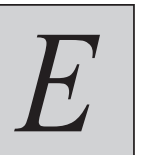

$\mathrm{n}$ países con alta producción de cultivo de camarón Penaeus vannamei, el uso de antibióticos incluidos en el alimento sigue siendo una práctica común sin restricción (Lunestad, Hannisdal \& Samuelsen, 2015). La información sobre el tipo y dosis de antibióticos utilizados en la acuicultura en el mundo es escasa. La oxitetraciclina (OTC) es uno de los tres antibióticos aprobados para su uso en la acuicultura de peces, de acuerdo a la Administración de Alimentos y Medicamentos de los Estados Unidos por sus siglas en inglés (FDA), para tratar enfermedades causadas por bacterias con capacidad patogénica (Vorbach, Chandesana, Derendorf \& Yanong, 2019). En el caso de México, los antibióticos más utilizados en la acuicultura, específicamente en el cultivo de camarón P. vannamei son, oxitetraciclina (OTC), florfenicol (FFC) y enrofloxacina (ENRO). Estos antibióticos han demostrado su eficacia en el tratamiento de vibriosis y de infecciones causadas por cocos Gram positivos y bacilos Gram negativos (Soto-Rodríguez, Gómez-Gil, Roque \& Lozano, 2008; LaraEspinoza, Espinosa-Plascencia, Rivera-Domínguez, AstorgaCienfuegos \& Acedo-Félix, 2015).

El uso de alimentos suplementados con vitaminas, proteínas adicionales y compuestos que promuevan el crecimiento de los organismos en cultivo, ha sido implementado en los últimos años. La generación de nuevas formulaciones de alimentos es una alternativa con la finalidad de prevenir posibles enfermedades que puedan afectarlos estando en cultivo, sin alterar las condiciones fisicoquímicas y ambientales para su crecimiento y sin afectar la relación costo-producción (Zhou, Thirumurugan, Wang, Lee \& Davis, 2016). Las fábricas de alimentos balanceados formulan alimento para camarón con altos estándares de calidad, con la finalidad de prolongar su vida de anaquel y mantener sus propiedades nutracéuticas. Dentro de la relación costo-producción, el alimento utilizado con los nutrientes y suplementos necesarios para el óptimo crecimiento de los organismos en cultivo, representa uno de los mayores costos de producción para los acuicultores $\left(\mathrm{O}^{\prime} \mathrm{Keefe}\right.$ \& Campabadal, 2015), principalmente las dietas adicionadas con antibióticos, debido a su proceso de manufactura. En este sentido, la porción no consumida del alimento (60-70\%) se descompone por hidratación, reduciendo su actividad química, biológica y microbiológica (Fox, Treece \& Sánchez, 2001). Factores como la solubilidad en el agua, la afinidad de las partículas orgánicas a quelarse y la fotodegradación, influyen en la persistencia de la OTC en los sistemas de cultivo, lo que favorece el desarrollo de resistencia a las bacterias que los habitan (Samuelsen et al., 2015).

La información que existe acerca de las prácticas empleadas en las granjas acuícolas sobre el manejo del alimento es escasa y es un aspecto que no está legislado. Los procedimientos para la adición de antibióticos, las condiciones de almacenamiento y el manejo de los alimentos medicados generalmente se implementan con base en el criterio del responsable técnico de la granja. Una práctica común en las unidades acuícolas es adicionar el antibiótico a un alimento comercial, empleando procedimientos con poca estandarización y control. Uno de estos procedimientos consiste en agregar el antibiótico en solución a través de un atomizador sobre el alimento comercial, o mezclarlo con el alimento y agitarlo por un corto tiempo. Estos procedimientos no cuentan con un control de calidad que garantice la homogenización del fármaco y la concentración final deseada de éste en el alimento, antes de su aplicación en los estanques de cultivo. Lo anterior, aunado a la escasez de investigaciones que proporcionen información relevante sobre las implicaciones que tiene la forma de adicionar el antibiótico en el alimento, su acumulación en los tejidos y su efecto en el control de lesiones internas y externas en el camarón $P$. vannamei, genera interés científico debido al desarrollo de resistencia bacteriana, principalmente en bacterias del género Vibrio, que son causantes de altas mortalidades de camarón. Por ello, en esta investigación se planteó evaluar dos procesos de adición de la OTC en el alimento para camarón, a fin de determinar su acumulación en los tejidos y el impacto en algunos parámetros biológicos y fisiológicos de $P$. vannamei.

\section{Materiales Y MÉtodos}

\section{Composición química del alimento para camarón}

Los alimentos adicionados con OTC y sin OTC fueron de origen comercial, preparados de acuerdo a los requerimientos nutricionales específicos para camarón. La composición química del alimento se muestra en la Tabla I.

Adición de oxitetraciclina en los alimentos para camarón Se utilizaron dos alimentos con distinto método de adición de OTC (OTC-1 y OTC-2). Para OTC-1, el antibiótico se

Tabla I. Composición del alimento comercial para camarón.

\begin{tabular}{|l|c|}
\hline \multicolumn{1}{|c|}{ Ingredientes } & Porcentaje (\%) \\
\hline Harina de pescado & 26.20 \\
\hline Harina de soya & 25.00 \\
\hline Gluten de maíz & 6.00 \\
\hline Aceite de pescado & 2.03 \\
\hline Lecitina de soya & 2.03 \\
\hline Mezcla vitamínica & 0.50 \\
\hline Vitamina C & 0.05 \\
\hline Aglutinante & 0.80 \\
\hline Fosfato monobásico & 4.36 \\
\hline Metionina & 0.02 \\
\hline Harina de camarón & 0.80 \\
\hline
\end{tabular}


adicionó en una fábrica de alimentos para producción animal, empleando el protocolo de fabricación estandarizado en la empresa. En el caso de OTC-2, la adición de OTC en el alimento se realizó siguiendo el protocolo establecido en la granja camaronícola, utilizando un alimento comercial para camarón libre de antibióticos. Para este procedimiento se preparó una solución de OTC (Sigma Aldrich, EUA) a una concentración de $8,000 \mathrm{mg} \mathrm{L}^{-1}$, disolviendo $8 \mathrm{~g}$ de OTC en $250 \mathrm{~mL}$ de agua de mar estéril, y esta solución se adicionó a $1 \mathrm{~kg}$ de alimento. Para su homogenización se utilizó una revolvedora mecánica (Cipsa Ultra 10) con motor Honda de $9 \mathrm{hp}$, mezclando durante $15 \mathrm{~min}$, obteniendo el alimento impregnado con la solución del antibiótico. Ambos alimentos se prepararon para tener una concentración final de $8,000 \mathrm{mg} \mathrm{Kg}^{-1}$ de OTC.

Análisis de oxitetraciclina en los alimentos para camarón La concentración de la OTC en los alimentos OTC-1 y OTC-2 se determinó previo a su administración a los organismos, empleando para el análisis un método de cromatografía de líquidos de alta resolución (HPLC) con detección ultravioleta, siguiendo el procedimiento descrito por Houglum, Larson \& Knutson (1997). Previamente se realizó el análisis de OTC en el alimento comercial para confirmar que estaba libre de antibióticos. Los análisis de las muestras de alimento se realizaron por duplicado incluyendo en cada corrida analítica, un control negativo (alimento sin antibióticos) y uno positivo (alimento adicionado con OTC a una concentración conocida).

\section{Diseño experimental del bioensayo}

Se realizó un bioensayo en una granja acuícola ubicada en Bahía de Kino, Sonora, México (28 48' 57.1" N $111^{\circ} 54^{\prime}$ 32.6 " W) durante un período de 30 días. Se emplearon 180 camarones juveniles de la especie $P$. vannamei que fueron tomados al azar de los estanques de la granja acuícola y colocados en peceras de $40 \mathrm{~L}$, registrando su peso inicial.

Los organismos se distribuyeron en tres grupos (OTC-1, OTC-2 y grupo control). Cada grupo estuvo conformado por seis peceras con 20 organismos por pecera.

Los alimentos con OTC (OTC-1 y OTC-2) se administraron a dos grupos de organismos, en dos fases: una primera de tratamiento de 14 días; y posteriormente una segunda de eliminación del antibiótico en la que se administró a ambos grupos de organismos alimento sin antibiótico por 16 días. Los organismos del grupo control se alimentaron con una dieta sin antibiótico durante todo el bioensayo. La tasa de alimentación fue al $4 \%$ de la biomasa, y se administró $30 \%$ del alimento por la mañana, $30 \%$ en la tarde y $40 \%$ en la noche, de acuerdo al protocolo de alimentación para organismos en etapa de engorde implementado en la granja acuícola.
Se evaluó dos veces al día la calidad del agua mediante la medición de parámetros fisicoquímicos como, $\mathrm{pH}$, temperatura, oxígeno disuelto (OD) y salinidad. Los niveles de nitrógeno amoniacal total (NAT) y la alcalinidad expresada como $\mathrm{CaCO}_{3}$ se cuantificaron una vez a la semana. Todas las peceras se mantuvieron con aireación constante. El alimento no consumido por los organismos, la colección de mudas y la materia orgánica y fecal se eliminaron diariamente mediante sifoneo, y se realizó recambio de agua de las peceras al $80 \%$, una vez a la semana.

\section{Determinación de los parámetros biológicos en los camarones}

Al inicio del bioensayo los organismos se pesaron en una balanza analítica digital Scout Pro 400 g EMAUS (México) y se midieron desde la parte proximal del rostro hasta el telson, empleando un vernier Foy con escala milimétrica (Querétaro, México). Durante el periodo del bioensayo (30 días) se realizaron muestreos cada tercer día, tomando tres camarones de cada pecera, los cuales se pesaron y midieron, registrando los datos para calcular la ganancia de peso, el incremento en talla, el porcentaje de sobrevivencia de los organismos, la Tasa Específica de Crecimiento (TEC) y el Factor de Conversión Alimenticia (FCA). Todas las ecuaciones correspondientes a estas mediciones se muestran en la Tabla II.

\section{Determinación de las lesiones externas e internas en los camarones}

La evaluación de las lesiones externas e internas en los organismos se realizó aplicando los criterios establecidos por Lightner (1996). La valoración de las lesiones externas se realizó tomando cada tercer día un camarón de cada pecera. Se registraron los cambios de coloración en la cutícula y/o pleópodos y pereiópodos, deformaciones en el rostro, exoesqueleto y necrosis o melanización en la cutícula, posteriormente se hizo la evaluación de las lesiones internas, extrayendo de cada organismo las branquias, intestino, ciego y hepatopáncreas (HP), observando estos órganos en fresco al microscopio (Nikon Eclipse E200, EUA). En las branquias se determinó la presencia de necrosis, ectoparásitos y bacterias filamentosas, en hepatopáncreas el daño en túbulos, contenido de lípidos y en intestino y ciego la presencia de gregarinas y gametocitos. Se utilizaron los criterios propuestos por Lightner (1996) para estimar las lesiones observadas al microscopio en los distintos órganos del camarón, utilizando una escala con valores categóricos de cero a cuatro, dependiendo del grado de severidad de las lesiones en los distintos órganos $(0=$ no existe lesión en el órgano y 4 = daño severo).

Para estimar el contenido de lípidos en el hepatopáncreas se consideraron los criterios descritos por Tapia-Salazar et al. (2012), utilizando una escala de L0 a L4, siendo L4 $=76-100 \%$ de los túbulos llenos de vacuolas de lípidos; L3 $=51-75 \%$ de 
Tabla II. Ecuaciones utilizadas en el cálculo de los parámetros biológicos de crecimiento del camarón Penaeus vannamei.

\begin{tabular}{|c|c|c|c|}
\hline Ecuación & Parámetros & Fórmulas utilizadas & Referencias \\
\hline 1 & Ganancia de peso (GP) & GP $=\frac{\text { Peso final }- \text { Peso inicial }}{\text { Días transcurridos }}$ & $\begin{array}{c}\text { Xu, Morris \& Samocha, } \\
2016\end{array}$ \\
\hline 2 & Incremento de talla (IT) & IT $=\frac{\text { Talla final - Talla inicial }}{\text { Días transcurridos }}$ & Xu et al., 2016 \\
\hline 3 & $\begin{array}{c}\text { Porcentaje de } \\
\text { sobrevivencia (S) (\%) }\end{array}$ & $\mathrm{S}=\frac{\text { (No.organismos vivos - No.organismos muertos) } 100}{\text { No.organismos en total }}$ & Li et al., 2007 \\
\hline 4 & $\begin{array}{c}\text { Tasa específica de } \\
\text { crecimiento (TEC) }\end{array}$ & TEC $=\left[\frac{\text { ln Peso húmedo final - ln Peso húmedo inicial }}{\text { Tiempo en días }}\right] \cdot 100$ & $\begin{array}{c}\text { Valverde-Moya \& } \\
\text { Alfaro-Montoya, 2015 }\end{array}$ \\
\hline 5 & $\begin{array}{c}\text { Factor de conversión } \\
\text { alimenticia (FCA) }\end{array}$ & FCA $=\frac{\text { Alimento total administrado }}{\text { Ganancia total de biomasa }}$ & $\begin{array}{c}\text { Arnold, Coman, Jackson } \\
\text { \& Groves, 2009 }\end{array}$ \\
\hline
\end{tabular}

lípidos; L2 = túbulos con moderada cantidad de lípidos (26$50 \%$ del nivel L4), L1 = escasa cantidad de lípidos $(10 \%$ del nivel L4) y L0 $=$ nula presencia de vacuolas de lípidos $(<10 \%$ del nivel L4).

\section{Aseguramiento de la calidad de los datos}

El método utilizado para la cuantificación de oxitetraciclina por HPLC fue desarrollado tomando como base la metodología publicada por Bermúdez-Almada, PérezTello, Valenzuela-Quintanar \& Vázquez-Moreno (1999) y validado en un estudio previo de nuestro grupo de trabajo (Espinosa-Plascencia, López-Arvayo, GonzálezCarrillo \& Bermúdez-Almada, 2012), con el propósito de establecer los parámetros de desempeño y compararlos con las especificaciones de validación de métodos analíticos (USDA, 1987). Los parámetros de desempeño del método empleado fueron: linealidad $\left(\mathrm{r}^{2}=0.9999\right)$; límite de detección $\left(0.01 \mu \mathrm{gmL}^{-1}\right)$; límite de cuantificación $\left(0.05 \mu \mathrm{gg}^{-1}\right)$; exactitud $(91.5 \pm 12.7 \%$ de recuperación para músculo y $90.1 \pm 17.3 \%$ para hepatopáncreas).

\section{Determinación de la acumulación de oxitetraciclina en los} tejidos de los camarones

La extracción de OTC de músculo y hepatopáncreas de los camarones se realizó siguiendo la metodología reportada por Gómez-Jiménez, Espinosa-Plascencia, Valenzuela-Villa \& Bermúdez-Almada (2008). La eliminación de lípidos y compuestos cromóforos interferentes de las muestras se hizo utilizando $10 \mathrm{~mL}$ de hexano grado reactivo (SigmaAldrich, EUA) en músculo y $16 \mathrm{~mL}$ en hepatopáncreas. La elución de OTC se llevó a cabo con $15 \mathrm{~mL}$ de una mezcla de acetonitrilo:metanol $(1: 1 \mathrm{v} / \mathrm{v})$ con $0.06 \%(\mathrm{p} / \mathrm{v})$ de butilhidroxianisol (BHA) y butilhidroxitolueno (BHT) (Sigma-Aldrich, EUA). El extracto obtenido se llevó a sequedad total en un baño de agua (VWR Scientific Products, EUA) a $40^{\circ} \mathrm{C}$, con un flujo de aire constante.
Las muestras secas se resuspendieron en $1 \mathrm{~mL}$ de una mezcla de ácido oxálico 0.02 M:acetonitrilo:metanol $(70: 27: 3 \mathrm{v} / \mathrm{v} / \mathrm{v})$, y se agitaron a alta velocidad por $30 \mathrm{~s}$ en un vórtex. Posteriormente, las muestras fueron sometidas a un proceso de sonicación por 30 min (Sonicador Cole Parmer, Chicago, IL.) y se centrifugaron a $2,800 \mathrm{~g}$ por $15 \mathrm{~min}$ a $4{ }^{\circ} \mathrm{C}$ (Heraeus Megafuge 8 Benchtop Thermo Scientific, EUA). Las muestras se filtraron usando acrodisc con tamaño de poro de $0.20 \mu \mathrm{m}$ (Acrodisc LC13 PVDF), y $200 \mu \mathrm{L}$ del extracto se inyectaron en el cromatógrafo de líquidos de alta resolución (HPLC) Varian Prostar 210, utilizando el programa Galaxie Chromatography Data System Versión 1.9 (Varian Co. Walnut Creek, CA. EUA). El HPLC fue conectado a un detector UV-Vis Prostar 325 programado a una longitud de onda de $365 \mathrm{~nm}$. Se utilizó una columna nucleosil $\mathrm{C}_{18}$ de 150 x $4.6 \mathrm{~mm}$ con tamaño de partícula de $5 \mu \mathrm{m}$ (Supelco, Co., St. Louis, MO. EUA) y la fase móvil consistió en una mezcla de ácido oxálico $0.02 \mathrm{M}$ :acetonitrilo:metanol $(70: 27: 3 \mathrm{v} / \mathrm{v} / \mathrm{v})$ a un flujo isocrático de $1 \mathrm{~mL} \mathrm{~min}{ }^{-1}$. El tiempo de corrida fue de $7 \mathrm{~min}$

\section{Análisis estadístico}

El análisis de los datos obtenidos en la medición de los parámetros fisicoquímicos del agua de las peceras, y de las evaluaciones biológicas y fisiológicas de los organismos se realizó mediante estadística descriptiva (media y desviación estándar). Se determinó una correlación entre los datos de acumulación de OTC y el desarrollo biológico de los organismos mediante una prueba de Pearson. Adicionalmente, se determinaron en los parámetros de FCA y TEC las diferencias significativas mediante un análisis de varianza de una vía. Los datos obtenidos de la acumulación de OTC en músculo y hepatopáncreas de los camarones fueron evaluados mediante un análisis de varianza de una vía en cada uno de los puntos de muestreo. Un valor de $\mathrm{p} \leq 0.05$ se consideró estadísticamente significativo. 


\section{Resultados}

Concentración de oxitetraciclina en alimento para camarón

El análisis de los alimentos con OTC-1 y OTC-2 mostró que la concentración de OTC en ambos fue menor al nivel teórico del antibiótico $\left(8,000 \mathrm{mg} \mathrm{Kg}{ }^{-1}\right)$. El alimento con (OTC-1) fabricado en la planta de alimentos balanceados tuvo una concentración de 4,684.38 $\mathrm{mg} \mathrm{Kg}^{-1}$ del antibiótico y el alimento adicionado con OTC en la granja (OTC-2) presentó una concentración de $776.81 \mathrm{mg} \mathrm{Kg}^{-1}$.

\section{Parámetros fisicoquímicos}

Durante el bioensayo, el valor más bajo registrado en la temperatura del agua de las peceras fue de $29.3 \pm 0.7^{\circ} \mathrm{C}$ por la mañana y el más alto de $34.8 \pm 1.6^{\circ} \mathrm{C}$ por la tarde, permaneciendo en promedio una temperatura de $31.70 \pm$ $2.25{ }^{\circ} \mathrm{C}$. El oxígeno disuelto (OD) presentó el valor más bajo de $3.6 \pm 1.0 \mathrm{mgL}^{-1}$ y el más alto de $5.8 \pm 0.4 \mathrm{mgL}^{-1}$. La salinidad mínima registrada de forma semanal en el agua de las peceras fue de $34.6 \pm 7.3 \%$ y el valor máximo fue de $40.8 \pm 2.4 \%$. La salinidad promedio durante el bioensayo fue de $37.97 \pm 0.53 \%$, mostrando los organismos una buena adaptación a estas condiciones. Los valores de los parámetros fisicoquímicos obtenidos durante todo el bioensayo se presentan en la Tabla III.

\section{Parámetros biológicos en los camarones}

En los organismos tratados con el alimento OTC-1, la ganancia de peso fue de $1.16 \pm 0.89 \mathrm{~g}$, siendo mayor a la que mostró el grupo de organismos que recibieron el alimento OTC-2 y el grupo control, que fue de $0.69 \pm 0.18$ y $0.73 \pm 0.04 \mathrm{~g}$ respectivamente. En relación a la talla, se encontró que en el grupo tratado con el alimento OTC-1 se tuvo un incremento de $4.40 \pm 1.83 \mathrm{~mm}$, observándose valores superiores a los mostrados por los grupos tratados con el alimento OTC-2, que fue de $3.03 \pm 1.55 \mathrm{~mm}$ y en el grupo control, que fue de $2.98 \pm 1.69 \mathrm{~mm}$. El desarrollo de los organismos durante el bioensayo se consideró adecuado en todos los grupos de tratamiento. Los resultados de la evaluación biológica de los camarones que conformaron los grupos estudiados se muestran

Tabla III. Parámetros fisicoquímicos del agua de mar utilizada en el bioensayo con camarón Penaeus vannamei tratado con alimento al que se le adicionó oxitetraciclina.

\begin{tabular}{|c|c|c|c|c|}
\hline Parámetros & Alimentos & $\begin{array}{c}\text { Valores } \\
(\mathrm{X} \pm \mathrm{DE}) \\
\end{array}$ & $\begin{array}{l}\text { Rangos de } \\
\text { referencia }\end{array}$ & Referencias \\
\hline $\mathrm{pH}$ & OTC-1 & $7.78 \pm 0.14$ & $6.8-8.7$ & Venkateswara-Rao, 2009 \\
\hline Temperatura & & $31.78 \pm 1.81$ & $27-31^{\circ} \mathrm{C}$ & Limsuwan, 2005 \\
\hline Salinidad & & $37.81 \pm 1.41$ & $1-50 \%$ & Li et al., 2008 \\
\hline Oxígeno disuelto & & $4.69 \pm 0.35$ & $3-5 \mathrm{mgL}^{-1}$ & Venkateswara-Rao, 2009 \\
\hline Nitrógeno amoniacal total & & $3.64 \pm 2.75$ & $1.2-6.5 \mathrm{mgL}^{-1}$ & $\begin{array}{l}\text { De la Mora, Villarreal-Delgado, Arredondo- } \\
\text { Figueroa, Ponce-Palafox \& Barriga-Sosa, 2003; } \\
\text { Franco, Blancheton, Deviller, Charrier \& Le, } 2004\end{array}$ \\
\hline Alcalinidad & & $100.17 \pm 21.04$ & $125-200 \mathrm{ppm}$ & Newman, 2015 \\
\hline $\mathrm{pH}$ & OTC-2 & $7.95 \pm 0.31$ & $6.8-8.7$ & Venkateswara-Rao, 2009 \\
\hline Temperatura & & $31.56 \pm 1.59$ & $27-31^{\circ} \mathrm{C}$ & Limsuwan, 2005 \\
\hline Salinidad & & $38.09 \pm 1.31$ & $1-50 \%$ & Li et al., 2008 \\
\hline Oxígeno disuelto & & $4.96 \pm 0.66$ & $3-5 \mathrm{mgL}^{-1}$ & Venkateswara-Rao, 2009 \\
\hline Nitrógeno amoniacal total & & $2.39 \pm 1.65$ & $1.2-6.5 \mathrm{mgL}^{-1}$ & De la Mora et al., 2003; Franco et al., 2004 \\
\hline Alcalinidad & & $106.17 \pm 25.35$ & $125-200 \mathrm{ppm}$ & Newman, 2015 \\
\hline
\end{tabular}

Tabla IV. Parámetros biológicos en camarón Penaeus vannamei tratado con distintos alimentos a los que se les adicionó oxitetraciclina.

\begin{tabular}{|l|c|c|c|c|c|c|}
\hline \multirow{2}{*}{ Grupos } & \multicolumn{2}{|c|}{ Peso (g) } & \multicolumn{2}{c|}{ Talla (mm) } & \multirow{2}{*}{ FCA } & \multirow{2}{*}{ TCE (\% g/d) } \\
\cline { 2 - 5 } & Inicial & Final & Inicial & Final & & \\
\hline OTC-1 & $3.37 \pm 1.36^{\mathrm{a}}$ & $6.72 \pm 1.21^{\mathrm{a}}$ & $66.68 \pm 7.86^{\mathrm{a}}$ & $85.7 \pm 5.43^{\mathrm{a}}$ & $0.94 \pm 0.91^{\mathrm{a}}$ & $4.20 \pm 2.47^{\mathrm{a}}$ \\
\hline OTC-2 & $3.36 \pm 1.09^{\mathrm{a}}$ & $6.18 \pm 2.59^{\mathrm{a}}$ & $66.88 \pm 6.93^{\mathrm{a}}$ & $82.0 \pm 15.61^{\mathrm{a}}$ & $0.93 \pm 0.83^{\mathrm{a}}$ & $3.79 \pm 1.18^{\mathrm{a}}$ \\
\hline Control & $3.59 \pm 1.22^{\mathrm{a}}$ & $7.17 \pm 2.25^{\mathrm{a}}$ & $68.45 \pm 7.07^{\mathrm{a}}$ & $88.2 \pm 10.27^{\mathrm{a}}$ & $0.77 \pm 0.44^{\mathrm{a}}$ & $4.16 \pm 2.38^{\mathrm{a}}$ \\
\hline
\end{tabular}

FCA: Factor de Conversión Alimenticia; TCE: Tasa de Crecimiento Específico. 
en la Tabla IV. No se encontraron diferencias significativas entre los valores obtenidos de TEC y FCA respecto a los alimentos administrados durante todo el bioensayo $(\mathrm{p} \geq 0.05)$. La ganancia de peso promedio semanal fue de $0.60 \pm$ $0.53 \mathrm{~g}$ y el crecimiento acumulado de $0.07 \pm 0.01 \mathrm{~mm}$ para los tres grupos. En este sentido, se determinó la relación de la concentración de OTC en los tejidos de camarón frente a parámetros como peso y talla mediante la prueba de Pearson. El análisis de los datos aplicando esta prueba estadística demostró que el alimento OTC-2 presentó una asociación entre la concentración del antibiótico y el incremento en la talla ( $\mathrm{p} \leq 0.05$ ), mientras que en los camarones alimentados con OTC-1 no se observó esta asociación en peso y talla, los resultados de la asociación se muestran en la Tabla V. Entre los aspectos de gran importancia que no se deben perder de vista se puede señalar, que el uso de alimentos con antibiótico propicia la contaminación de los estanques, generación de residuos de antibióticos en los tejidos de los organismos y el desarrollo de resistencia bacteriana.

La sobrevivencia de los organismos tratados con el alimento OTC-1 fue de $99.72 \%$, para los que recibieron el tratamiento OTC-2 y el grupo control fue de 100\%. Estadísticamente se demostró que no hubo diferencia significativa en la sobrevivencia de los organismos con respecto a los tratamientos administrados.

Evaluación de lesiones internas y externas en los camarones Se encontró que los organismos no presentaron lesiones externas en los grupos OTC-1, OTC-2 y el control, esto se atribuyó al bajo número de camarones colocados en cada pecera, lo que evitó el hacinamiento. La observación de lesiones internas en el intestino de los organismos evaluados de los grupos OTC-1 y OTC-2, mostró la presencia de gregarinas en el $1.11 \%$ del total de los organismos, y no se observaron gametocitos. Uno de ellos presentó quistes de parásitos en la región del ciego; los camarones pueden alojar estos parásitos dependiendo del entorno en que se cultivan. La Figura 1 muestra fotografías microscópicas de órganos de camarón de los grupos tratados con los alimentos medicados (OTC-1 y OTC-2), no observándose diferencias entre ambos grupos y con respecto al control. En el hepatopáncreas, se observaron los túbulos con un adecuado contenido de lípidos en el 95\% de los organismos; las branquias no presentaron ectoparásitos o bacterias filamentosas; solo se detectó necrosis en el 1.94\% de los camarones. El resto de los organismos analizados presentaron mínimas lesiones externas e internas. En la microscopía correspondiente al intestino se observa un gran número de compuestos cromóforos y ausencia de parásitos, $\mathrm{y}$ en la región del ciego se aprecia la ausencia de quistes.

\section{Concentración de oxitetraciclina en los tejidos de camarón Penaeus vannamei}

Los niveles de acumulación de OTC en músculo y hepatopáncreas, así como el tiempo requerido para su eliminación de los tejidos se presentan en las Tablas VI y VII. En las muestras del grupo OTC-1, la concentración máxima $\left(\mathrm{C}_{\text {máx }}\right)$ de $\mathrm{OTC}$ en músculo se obtuvo al noveno día de tratamiento y en hepatopáncreas al décimo día. Mientras que en el grupo de organismos que recibieron el alimento OTC-2, la $\mathrm{C}_{\text {máx }}$ se alcanzó el décimo día, tanto en músculo, como en hepatopáncreas. Se observó que la acumulación de OTC en el músculo de los organismos que recibieron el alimento OTC-2 presentó diferencias significativas en los

Tabla V. Correlación de Pearson en la acumulación de oxitetraciclina en los tejidos del camarón Penaeus vannamei y parámetros biológicos.

\begin{tabular}{|c|c|c|c|c|c|c|c|}
\hline & & \multicolumn{2}{|c|}{ Músculo } & \multicolumn{2}{|c|}{ Hepatopáncreas } & \multirow[t]{2}{*}{ Peso } & \multirow[t]{2}{*}{ Talla } \\
\hline & & OTC-1 & OTC-2 & OTC-1 & OTC-2 & & \\
\hline Músculo & OTC-2 & $\begin{array}{c}\mathrm{P}=0.000^{*} \\
0.619\end{array}$ & & & & & \\
\hline \multirow{2}{*}{ Hepatopáncreas } & OTC-1 & $\begin{array}{c}\mathrm{P}=0.000^{*} \\
0.856\end{array}$ & $\begin{array}{c}\mathrm{P}=0.000^{*} \\
0.560\end{array}$ & & & & \\
\hline & OTC-2 & $\begin{array}{c}\mathrm{P}=0.009^{*} \\
0.456\end{array}$ & $\begin{array}{c}\mathrm{P}=0.000^{*} \\
0.872\end{array}$ & $\begin{array}{c}\mathrm{P}=0.004^{*} \\
0.507\end{array}$ & & & \\
\hline Peso & & $\begin{array}{c}\mathrm{P}=0.220 \\
-0.209\end{array}$ & $\begin{array}{c}\mathrm{P}=0.286 \\
0.183\end{array}$ & $\begin{array}{c}\mathrm{P}=0.378 \\
-0.154\end{array}$ & $\begin{array}{c}\mathrm{P}=0.438 \\
0.142\end{array}$ & & \\
\hline Talla & & $\begin{array}{c}\mathrm{P}=0.608 \\
-0.088\end{array}$ & $\begin{array}{c}\mathrm{P}=0.061 \\
0.315\end{array}$ & $\begin{array}{c}\mathrm{P}=0.916 \\
-0.018\end{array}$ & $\begin{array}{c}\mathrm{P}=0.102 \\
0.294\end{array}$ & $\begin{array}{c}\mathrm{P}=0.000^{*} \\
0.961\end{array}$ & \\
\hline TCE & & $\begin{array}{c}\mathrm{P}=0.741 \\
-0.057\end{array}$ & $\begin{array}{c}\mathrm{P}=0.859 \\
-0.031\end{array}$ & $\begin{array}{c}\mathrm{P}=0.539 \\
-0.107\end{array}$ & $\begin{array}{c}\mathrm{P}=0.484 \\
-0.128\end{array}$ & $\begin{array}{c}\mathrm{P}=0.265 \\
-0.191\end{array}$ & $\begin{array}{c}\mathrm{P}=0.212 \\
-0.213\end{array}$ \\
\hline
\end{tabular}

TCE: Tasa de Crecimiento Específico; *Valor de $\mathrm{p} \leq 0.05$. 


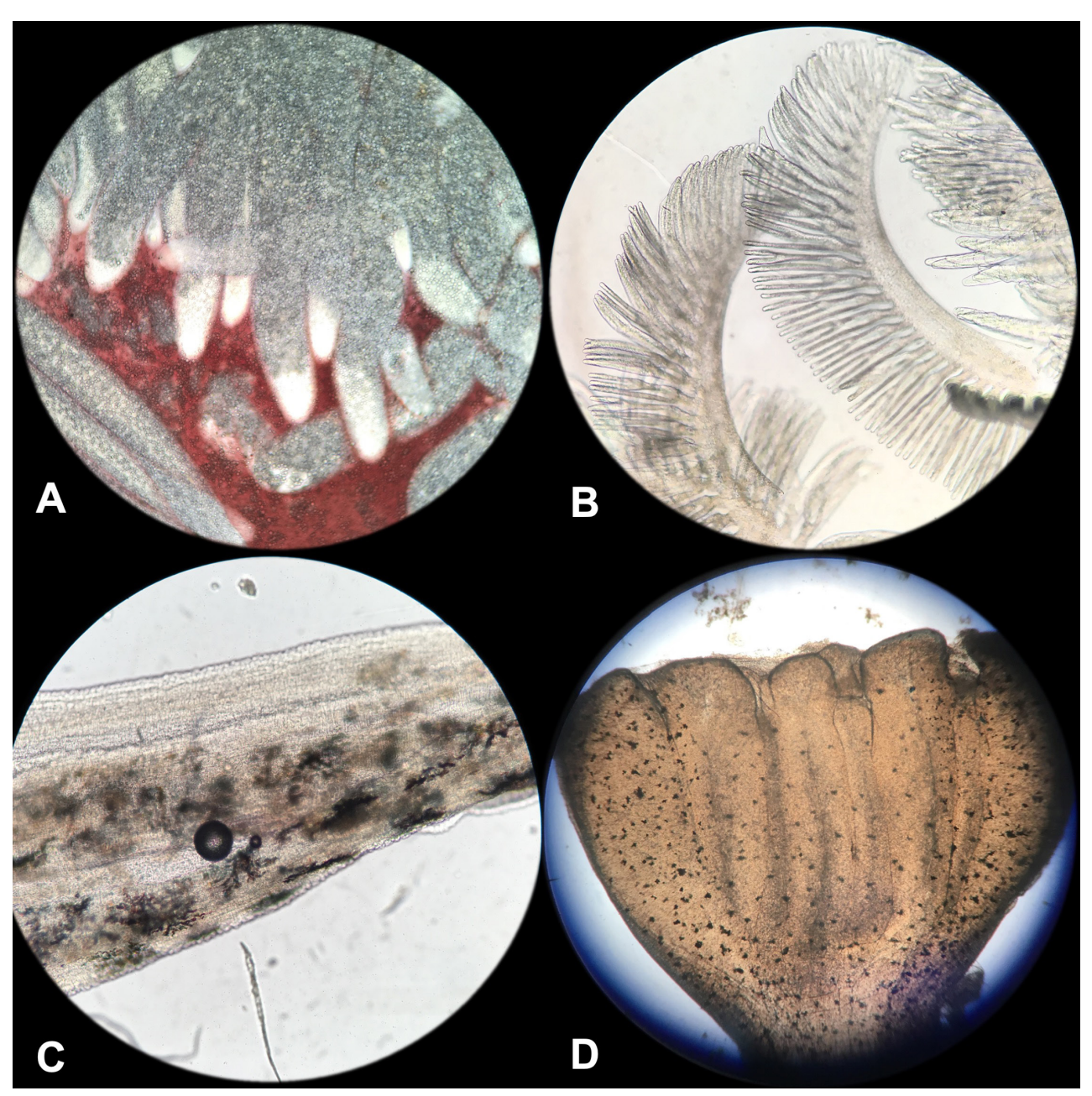

Figura 1. Microscopía 40x de distintos órganos del camarón Penaeus vannamei, para la evaluación de lesiones internas. (A)Túbulos del hepatopáncreas. (B) Branquias del camarón. (C) Sección del intestino del camarón. (D) Sección del ciego del intestino del camarón. Elaboración personal.

primeros seis muestreos $(\mathrm{p} \leq 0.05)$, en comparación con la acumulación del antibiótico que se obtuvo en el grupo que recibió el alimento OTC-1. Mientras que en el hepatopáncreas la concentración de OTC reflejó diferencias significativas únicamente en el muestreo ocho, correspondiente al día 24 del tratamiento, al comparar ambos grupos. Durante la etapa de retiro del antibiótico, en ambos tejidos evaluados se encontró que la eliminación fue más eficiente en los organismos que recibieron el tratamiento con OTC-1 comparado con el tratamiento OTC-2 (Tablas VI y VII).

Durante la etapa posterior al tratamiento con OTC, los organismos tratados con los alimentos OTC-1 y OTC-2 requirieron quince días para la eliminación del antibiótico del músculo; mientras que para la eliminación en el hepatopáncreas se requirieron doce días en el grupo que recibió el alimento OTC-1 y quince días en los organismos tratados con el alimento OTC-2 (Tablas VI y VII). Es decir, que después de esos tiempos el antibiótico ya no estaba presente o bien se encontraba por debajo del límite mínimo

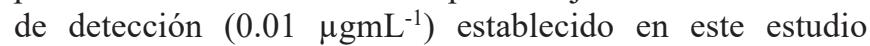
para el método analítico. Estadísticamente no se observó diferencia significativa entre los grupos OTC-1 y OTC-2, en las concentraciones de OTC acumuladas durante el período de retiro del antibiótico.

\section{Discusión}

La finalidad de formular un alimento con una concentración adecuada de antibiótico es la de aplicar una terapia apropiada en los cultivos de camarón, cuando se requiere contener un brote infeccioso por patógenos emergentes bacterianos. Sin embargo, para obtener un alimento medicado que contenga la concentración deseada de antibiótico se deben cumplir ciertos requisitos. Entre los factores que influyen en la 
Tabla VI. Acumulación de oxitetraciclina en músculo del camarón Penaeus vannamei.

\begin{tabular}{|c|c|c|c|c|}
\hline Tejido & Muestreos & Alimentos & $C_{\text {máx }}\left(\mu g g^{-1)}\right.$ & ANOVA *p $(\leq 0.05)$ \\
\hline \multirow{13}{*}{ Músculo } & \multirow{2}{*}{1} & OTC-1 & $2.88 \pm 0.40$ & $\mathrm{p} \leq 0.05$ \\
\hline & & OTC-2 & $0.44 \pm 0.08$ & \\
\hline & 2 & OTC-2 & $3.83 \pm 0.33$ & \\
\hline & 3 & OTC-1 & $16.09 \pm 1.80$ & $\mathrm{p} \leq 0.05$ \\
\hline & \multirow{2}{*}{4} & OTC-1 & $9.74 \pm 0.80$ & $\mathrm{p} \leq 0.05$ \\
\hline & & OTC-2 & $6.62 \pm 0.87$ & \\
\hline & \multirow{2}{*}{5} & OTC-1 & $1.38 \pm 0.30$ & $\mathrm{p} \leq 0.05$ \\
\hline & & OTC-2 & $6.48 \pm 0.60$ & \\
\hline & 7 & OTC-2 & $0.38 \pm 0.01$ & \\
\hline & \multirow{2}{*}{8} & OTC-1 & ND & - \\
\hline & & OTC-2 & ND & \\
\hline & \multirow{2}{*}{9} & OTC-1 & ND & - \\
\hline & & OTC-2 & ND & \\
\hline
\end{tabular}

ND: No detectado.

Tabla VII. Acumulación de oxitetraciclina en el hepatopáncreas del camarón Penaeus vannamei.

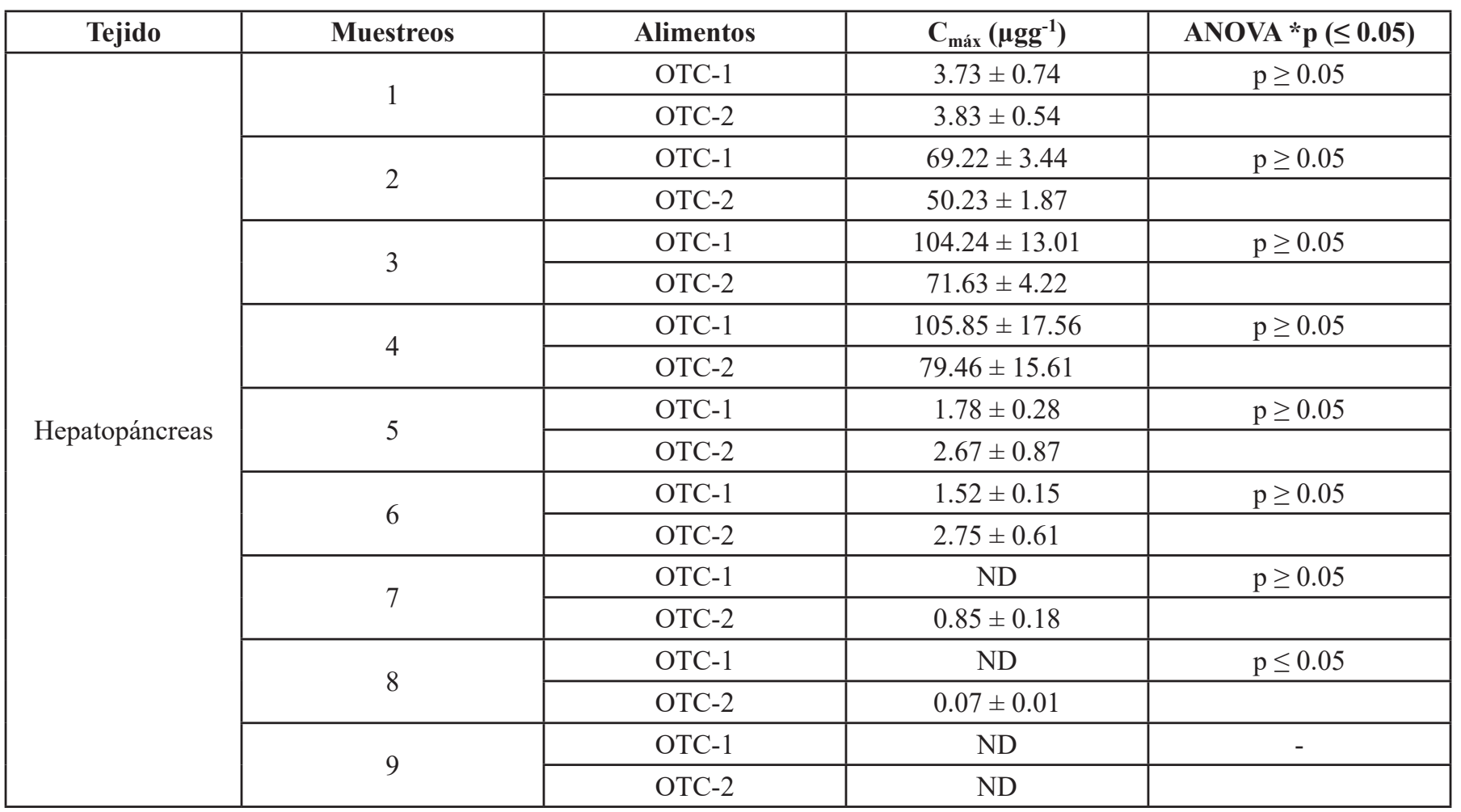

ND: No detectado. 
incorporación adecuada de antibiótico está su composición y la cantidad de los suplementos que integran la formulación del alimento. Además de la forma, tamaño y densidad de las partículas, la presencia de ingredientes líquidos, el peso de los ingredientes y su homogeneización así como el orden en el que éstos son mezclados, son factores que contribuyen a que el antibiótico pueda no ser distribuido correctamente o no se mantenga estable dentro del alimento. Además, existen factores externos como la temperatura y la humedad durante el almacenamiento, los niveles de $\mathrm{CO}_{2}$, presencia de hongos e insectos, que pueden alterar la naturaleza del alimento (FDA, 1994).

La diferencia en la concentración de la OTC teórica y la determinada analíticamente en el alimento OTC-2, demostró que el procedimiento de adición del antibiótico empleado en la granja no fue el adecuado, provocando que éste no se incorporara correctamente y tuviera una concentración menor al $10 \%$ del nivel teórico calculado. En el caso del alimento preparado industrialmente (OTC-1), también se observó que la adición del antibiótico no fue eficiente dado que sólo se recuperó el $58 \%$ de la concentración adicionada. Si se considera que el alimento representa entre el 50 y $70 \%$ de los costos de producción en el cultivo de camarón, es importante garantizar que este sea lo más eficiente posible (Faillace, Vergara \& Suárez, 2016).

El preparar alimentos con antibiótico en las granjas de cultivo de camarón con el propósito de controlar las infecciones bacterianas es una práctica común que se lleva a cabo en la industria acuícola, y que tiene como finalidad reducir los costos de producción. Sin embargo, estos alimentos pueden no contener la concentración adecuada del antibiótico, o presentar irregularidad en el tamaño de las partículas, y no ser uniforme, lo que incrementa el riesgo de que el antibiótico sea lixiviado en el agua de los estanques. Aunado a esto, la administración de alimentos suplementados con antibiótico en dosis subterapéuticas puede provocar el desarrollo de resistencia bacteriana en patógenos emergentes, e incrementar el índice de mortalidad de los camarones en cultivo, debido al nulo efecto de los tratamientos con antibióticos ante una infección bacteriana (Achupallas, Zhou \& Davis, 2016).

Por ello, se considera la alimentación de los organismos en cultivo como uno de los factores más importantes involucrados en su producción, que debe mantenerse bajo una observación cuidadosa y permanente (Achupallas, 2000). Es recomendable llevar a cabo el análisis del alimento adicionado con el antibiótico y sin antibiótico, empleando métodos confiables para confirmar la concentración indicada, o bien, la ausencia de antibióticos en el alimento. Un deficiente control de calidad durante la fabricación del alimento para camarón puede ocasionar que alimentos sin medicar presenten residuos de antibióticos, o bien un nivel mayor o menor del antibiótico en los alimentos adicionados (González-Carrillo, Espinosa-Plascencia \& BermúdezAlmada, 2010).

Una de las principales limitaciones que impiden asegurar la concentración correcta de los antibióticos en el alimento para camarón es la falta de metodologías analíticas suficientemente sensibles y confiables para la identificación y cuantificación de estos compuestos durante su proceso de elaboración y en el producto terminado. El empleo de metodologías analíticas validadas, como HPLC en la determinación de la OTC en el alimento para camarón, es una herramienta que proporciona buenos resultados, por la sensibilidad y precisión en la detección de este antibiótico en matrices complejas como lo es el alimento para camarón. Esta metodología analítica puede contribuir a mantener un mejor control de calidad en el alimento destinado a especies acuáticas en cultivo, para que su aplicación sea segura, sin causar contaminación en los ecosistemas y el desarrollo de resistencia bacteriana (González et al., 2010).

En relación a los parámetros fisicoquímicos durante el cultivo, Li et al. (2008) y Burbano-Gallardo et al. (2015) expusieron que $P$. vannamei es una especie capaz de resistir intervalos de salinidad de $1-50 \%$, sin que se afecte su desarrollo, lo cual se pudo constatar en este estudio, donde tuvieron un adecuado desarrollo a una salinidad promedio de $37.97 \pm 0.53 \%$. Las altas salinidades causan estrés y obligan al camarón a utilizar recursos energéticos para restablecer el equilibrio osmótico causado por la diferencia de osmolaridad entre los fluidos internos del organismo y el agua marina (Yohenia \& Bolaños, 2013). En este estudio los parámetros fisicoquímicos que prevalecieron en el agua de las peceras no mostraron mayores diferencias al compararlos con los valores reportados por otros autores, quienes los señalan como óptimos para el desarrollo y sobrevivencia de P. vannamei (Tabla III).

Torres \& Zaragoza (2002) reportaron que los antibióticos promueven el crecimiento de los camarones porque modifican cuantitativa y cualitativamente la microbiota intestinal. Esto ocurre debido a que las bacterias patógenas y la microbiota normal del intestino se ven disminuidas por la acción del antibiótico, reflejándose esto en una mayor efectividad de absorción y asimilación de los nutrientes, generando una mejor conversión del alimento en biomasa y aumento de la talla de los organismos. La calidad del alimento y la cantidad ingerida influye en el peso y tamaño, ya que este provee los nutrientes necesarios para su óptimo desarrollo, como lo mencionan Zhou et al. (2016). En este sentido, el factor de conversión alimenticia es uno de los indicadores más importantes en la producción de camarón, ya que permite conocer si se alimentan y desarrollan adecuadamente. 
Boyd et al. (2000) reportaron que el FCA debe mantenerse entre 1.5-2.0, para tener un adecuado crecimiento de los organismos, y sus requerimientos energéticos y proteicos cubiertos. Mientras que otros autores mencionaron que en camarones $P$. vannamei alimentados con dietas con aditivos, un FCA en el rango de $1.22 \pm 0.12$ a $1.29 \pm 0.11$ puede ser adecuado (ApunMolina et al., 2015; Carvalho, Haruo-Ota, Kadry, Tacon \& Lemos, 2016). Los resultados obtenidos en el FCA de este estudio fueron cercanos a los valores recomendados por estos autores, y la diferencia pudo ser atribuida a la variabilidad en el peso inicial de los organismos juveniles empleados, que fue de 2.45 a $5.91 \mathrm{~g}$. Mientras que Fóes, Krummenauer, Lara, Poersh \& Wasieslesky (2016) señalaron que la administración de alimento con antibióticos mejora el FCA a largo plazo. Bajo las condiciones establecidas en el bioensayo, los parámetros de ganancia de peso, crecimiento, FCA y sobrevivencia se consideraron adecuados en los grupos tratados con alimentos adicionados con OTC y los valores fueron superiores a los del grupo de control administrado con alimento sin antibiótico.

La alta sobrevivencia obtenida en el bioensayo, que fue de 99.8 y $100 \%$ para los grupos OTC-1 y OTC-2 respectivamente, pudo ser el resultado de la baja densidad de organismos que se mantuvieron en las peceras y el haberlos elegido para este ensayo en la etapa juvenil que es cuando están mejor adaptados a las condiciones ambientales. Los porcentajes de sobrevivencia fueron adecuados y superiores a los obtenidos por otros autores en bioensayos con condiciones similares, donde se reportan valores de sobrevivencia menores al $90 \%$ en camarón P. vannamei (Gutiérrez-Dagnino et al, 2015; Fóes et al., 2016).

Gong, Jiang, Lawrence, González-Félix \& Pérez-Velázquez, (2004) reportaron que para $P$. vannamei los lípidos almacenados en el hepatopáncreas, representan una reserva suficiente de energía que podrá ser utilizada durante la exposición a condiciones externas, por ello es importante que se mantenga un nivel adecuado de lípidos en este órgano. Tapia-Salazar et al. (2012) reportaron que la atrofia en los túbulos del hepatopáncreas se relaciona directamente con la presencia de infecciones bacterianas. Otro estudio realizado por Cuartas, Díaz \& Petriella (2002) reportaron que las deformaciones de los túbulos, inflamación y aumento de la actividad celular en estos pueden ser causadas por estrés nutricional, presencia de patógenos o alteraciones del medio ambiente. Sin embargo, en nuestro estudio no se observaron manifestaciones de atrofia severa en los túbulos, por lo que se descartó una infección bacteriana y el desarrollo de los organismos en el bioensayo fue óptimo.

El diagnóstico oportuno de lesiones internas o externas en los organismos ocasionadas por bacterias, favorece la correcta aplicación de terapias y dosis adecuadas de antibióticos. Durante la etapa de tratamiento en el bioensayo, donde se administró el alimento con antibiótico, la concentración de la OTC en los distintos tejidos (músculo y hepatopáncreas) presentó variaciones, esto fue debido al crecimiento de los organismos, ya que durante esta etapa ocurrieron procesos de muda y los camarones dejan de alimentarse, lo que provoca cambios en su metabolismo y actividad celular, reflejándose en las variaciones obtenidas en la acumulación de OTC en los tejidos (Uno, Aoki, Kleechaya, Tanasomwang \& Ruangpan, 2006; Bermúdez-Almada, Espinosa-Plascencia, SantiagoHernández, Barajas-Borgo \& Acedo-Félix, 2014).

Variaciones similares en la acumulación de la OTC fueron reportadas por Gómez-Jiménez et al. (2008) en un estudio realizado con camarón $P$. vannamei alimentado con una dieta con OTC a 5,000 $\mathrm{mgKg}^{-1}, \mathrm{y}$ mantenido bajo condiciones de laboratorio, encontrándose acumulaciones de OTC en el hepatopáncreas de $194.37 \pm 16.11{\mu g g g^{-1}}^{y}$ en músculo de $33.54 \pm 11.19 \mu \mathrm{gg}^{-1}$, valores similares a los que se detectaron en los tejidos de los organismos que recibieron la dieta de OTC-1. Cuartas et al. (2002) señalaron que aun cuando las concentraciones de OTC en hepatopáncreas son altas, su eliminación se acelera debido a la función que este órgano tiene en el metabolismo del camarón, que es la asimilación del alimento mediante un proceso integrado en el que participan enzimas digestivas, digestión y absorción de nutrientes, almacenamiento y disposición de productos de desecho.

Existen estudios que han evaluado la acumulación de OTC en músculo y hepatopáncreas de camarón (Gómez-Jiménez et al., 2008; Bermúdez-Almada et al., 2014), estos autores señalan que la acumulación de la OTC en los tejidos depende de diversos factores. Dentro de estos están los abióticos (temperatura, salinidad y oxígeno disuelto, entre otros) y los biológicos, donde interviene el metabolismo que se considera muy importante en la acumulación del antibiótico, ya que durante los períodos de muda, los camarones dejan de alimentarse, influyendo directamente en la acumulación y por ende en la $\mathrm{C}_{\text {máx }}$ alcanzada en los distintos tejidos. También la $\mathrm{C}_{\text {máx }}$ alcanzada dependerá de la pureza de la molécula del antibiótico, el proceso de adición del antibiótico al alimento y la efectividad del mecanismo de acción del antibiótico (Ma et al., 2019).

Es importante determinar la $\mathrm{C}_{\text {máx }}$ alcanzada de la OTC en los tejidos de los organismos, dado que estos valores se comparan con las Concentraciones Mínimas Inhibitorias (CMI) detectadas en las bacterias aisladas de esos mismos tejidos, y se puede conocer si la concentración del antibiótico acumulada en los tejidos es suficiente para inhibir el crecimiento bacteriano. Las bacterias aisladas del camarón Penaeus vannamei en esta investigación presentaron valores de CMI de $0.5 \mu \mathrm{gmL}^{-1}$ para OTC en especies de Vibrio (Datos en prensa, Latin American Journal of Aquatic Research), lo que demuestra la susceptibilidad a la OTC 
de las poblaciones bacterianas aisladas de los organismos estudiados. Mientras que en un estudio realizado por Santiago-Hernández (2009) se reportaron acumulaciones de OTC en músculo de $27.9 \pm 1.67 \mu \mathrm{gg}^{-1}$ y en hepatopáncreas de camarón de $212.5 \pm 0.4{\mu \mathrm{gg}^{-1}}^{-1}$, que fueron consideradas adecuadas cuando se relacionaron con las CMI de la OTC, y oscilaron entre 0.75 a $100 \mu \mathrm{gmL}^{-1}$ en bacterias Vibrio sp aisladas de un sistema de cultivo de camarón. Mientras que Roque, Molina-Aja, Bolan-Mejia \& Gómez-Gil (2001) evaluaron la sensibilidad a 15 antibióticos mostrada por 144 cepas de Vibrio sp aisladas también de un sistema de cultivo de camarón, cuyos resultados mostraron que el mayor número de cepas fueron resistentes a la OTC y la concentración requerida de este antibiótico para lograr su inhibición fue de $304 \mu \mathrm{gmL}^{-1}$, valor superior a las concentraciones máximas que generalmente se acumulan en los tejidos.

Otro aspecto importante de resaltar es la relevancia que tiene el establecimiento del período de retiro de la OTC en los tejidos antes de su cosecha, con el propósito de evitar la presencia de residuos de antibióticos que rebasen los límites máximos establecidos en otros países como la FDA $\left(0.2 \mu \mathrm{gg}^{-1}\right)$ y la Unión Europea $\left(0.1 \mu \mathrm{gg}^{-1}\right)$, que pueda repercutir en un rechazo del producto con las consecuentes implicaciones comerciales, así como un riesgo a la salud de la población en general por el desarrollo de resistencia bacteriana.

\section{Conclusiones}

Los parámetros fisicoquímicos mantenidos durante el bioensayo favorecieron una alta sobrevivencia de los camarones $P$. vannamei, y la evaluación de los parámetros biológicos arrojó resultados favorables para los organismos tratados con los alimentos OTC-1 y OTC-2 con distintas concentraciones del antibiótico.

El proceso industrial para la elaboración del alimento OTC-1 mostró ser ineficiente debido a que se detectó que el alimento no contenía la concentración indicada de oxitetraciclina, por lo que es necesario un mayor control de calidad en el proceso de elaboración del alimento medicado, que incluya análisis de rutina empleando técnicas analíticas confiables para asegurar la concentración del antibiótico en el producto terminado que será utilizado en el tratamiento de enfermedades bacterianas en camarón de cultivo.

El procedimiento que se utilizó para la preparación del alimento OTC-2 en la granja no fue adecuado para obtener la concentración requerida de OTC. Por lo que se sugiere que no se realicen este tipo de prácticas en las granjas camaronícolas, ya que si se aplican dosis subterapéuticas a los organismos en cultivo, esto podría representar un impacto de contaminación con antibióticos al entorno de la producción, lo que favorece el desarrollo de resistencia bacteriana de agentes patógenos, representando un riesgo a la salud humana, además de afectar la producción del camarón.

Con base en los resultados obtenidos en este estudio, se identifica la importancia de continuar realizando investigaciones en este campo, con el propósito de recomendar la implementación de sistemas de calidad en las plantas de fabricación de alimentos destinados a la producción acuícola, así como evitar prácticas inadecuadas de medicación de alimento en las granjas de cultivo de camarón, esto con el propósito de que los alimentos adicionados con antibiótico contengan la concentración adecuada que pueda asegurar terapias efectivas en el control de enfermedades bacterianas en los cultivos acuícolas, minimizando el impacto al medio ambiente y el riesgo a la salud humana por el desarrollo de resistencia bacteriana.

\section{REFERENCIAS}

Achupallas, J. M., Zhou, Y. \& Davis, D. A., (2016). Pond production of Pacific white shrimp, Litopenaeus vannamei, fed grain distillers dried yeast. Aquaculture Nutrition, 22, 1222-1229. https://doi.org/10.1111/ anu. 12359

Achupallas, J. (2000). Tecnología de alimentos para camarón. En: Civera-Cerecedo, R., Pérez-Estada, C. J., RicqueMarie, D. y Cruz-Suárez, L. E. (Eds.) Avances en Nutrición Acuícola IV. Memorias del IV Simposium Internacional de Nutrición Acuícola. Noviembre 15-18,1998. La Paz, B.C.S., México. Disponible en: https://www.uanl.mx/ utilerias/nutricion_acuicola/IV/archivos/31achup.pdf

Apun-Molina, J. P., Santamaría-Miranda, A., Luna-González, A., Ibarra-Gámez, J. C., Medina-Alcantar, V. \& Racotta, I. (2015). Growth and metabolic responses of whiteleg shrimp Litopenaeus vannamei and Nile tilapia Oreochromis niloticus in polyculture fed with potential probiotic microorganisms on different schedules. Latin American Journal Aquatic Research, 43(3), 435-445. http://doi. org/10.3856/vol43-issue3-fulltext-5

Arnold, J. S., Coman, F. E., Jackson, C. J. \& Groves, S. A. (2009). High-intensity, zero water exchange production of juvenile tiger shrimp, Penaeus monodon: An evaluation of artificial substrates and stocking density. Aquaculture, 293(1-2), 43 48. https://doi.org/10.1016/j.aquaculture.2009.03.049

Bermúdez-Almada, M. C., Pérez-Tello, M. G., ValenzuelaQuintanar, A. I. \& Vázquez-Moreno, L. (1999). Oxytetracycline residues in cultured white shrimp tissue by HPLC and a microbial receptor assay. Journal of Food Science, 64(4), 638-940. https://doi. org/10.1111/j.1365-2621.1999.tb15100.x

Bermúdez-Almada, M. C., Espinosa-Plascencia, A., SantiagoHernández, M. L., Barajas-Borgo, C. J. \& Acedo-Félix, E. (2014). Comportamiento de oxitetraciclina en camarón de cultivo Litopenaeus vannamei y la sensibilidad a tres antibióticos de bacterias de Vibrio aisladas de los 
organismos. Revista Biotecnia, 16(3), 29-37. https://doi. org/10.18633/bt.v16i3.138

Boyd, C. E., Treece, G., Engle, R. C., Valderrama, D., Lightner, V. D., Pantoja, C. R., Fox, J., Sánchez, D., Otwell, S., Garrido, L., Garrido, V. \& Benner, R. (2000). Consideraciones sobre la calidad del agua y del suelo en cultivos de camarón. En: Haws M. C. y C. E. Boyd (ed). Métodos para mejorar la camaronicultura en Centroamérica. p 1-30. Disponible en: http://repositorio. uca.edu.ni/2279/1/2001_m\%C3\%A9todo_para_mejorar la_camaronicultura.pdf

Burbano-Gallardo, E., Imués-Figuera, M. A., GonzálezLegarda, E. A., Brito, L. O., Olivera-Galvez, A. \& Vinatea-Arana, L. A. (2015). Supervivencia de poslarvas de Litopenaeus vannamei sometidas a la prueba de estrés osmótico y su relación con el estado de muda. Revista de Biología Marina y Oceanografía, 50(2), 323-329. http:// dx.doi.org/10.4067/S0718-19572015000300010

Carvalho, R. A. P. L. F., Haruo-Ota, R., Kadry, V. O., Tacon, A. G. J. \& Lemos, D. (2016). Apparent digestibility of protein, energy, and amino acids of six protein sources included at three levels in diets for juvenile white shrimp Litopenaeus vannamei reared in high performance conditions. Aquaculture, 465, 223-234. https://doi.org/10.1016/j. aquaculture.2016.09.010

Cuartas, E. I., Díaz, A. C. \& Petriella, A. M. (2002). Estudio morfológico e histológico del hepatopáncreas del langostino Pleoticus muelleri (Bate) (Crustacea, Penaeoidea). Revista de Investigación y Desarrollo Pesquero, 15, 5-13. Disponible en: http://hdl.handle.net/1834/1702

De la Mora, G., Villarreal-Delgado, E., Arredondo-Figueroa, J., Ponce-Palafox, J. \& Barriga-Sosa, I. (2003). Evaluación de algunos parámetros de calidad del agua en un sistema cerrado de recirculación para la acuicultura, sometido a diferentes cargas de biomasa de peces. Hidrobiológica, 13(4), 247-253. http://www.scielo.org.mx/pdf/hbio/v13n4/ v13n4a1.pdf

Espinosa-Plascencia, A., López-Arvayo, P. J., GonzálezCarrillo, H. H. \& Bermúdez-Almada, M. C. (2012). Efecto del congelado y cocinado sobre residuos de oxitetraciclina en camarón de cultivo. Revista Biotecnia, 8(3), 12-21. https://doi.org/10.18633/bt.v13i3.94

Faillace, B. J. F., Vergara, R. \& Suárez, A. (2016). Evaluación de una fórmula alimenticia para camarón de cultivo ( $L$. vannamei) con inclusión de proteína vegetal a base de harina de soya. Revista AquaTIC, 44, 12-29. Disponible en: http:/www.revistaaquatic.com/ojs/index.php/aquatic/ article/view/271/254

Fóes, G., Krummenauer, D., Lara, G., Poersh, L. \& Wasieslesky, W. (2016). Long term storage and the compensatory growth of white shrimp Litopenaeus vannamei in aquaculture ponds. Latin American Journal of Aquatic Research, 44, 588-594.

Food \& Drug Administration (FDA) (1994). Control de Calidad de insumos y dietas acuícolas. Capítulo 15. Nutrición y control de calidad, un enfoque integral. Disponible en:
http://www.fao.org/3/ab482s/AB482S00.htm\#TOC

Fox, J., Treece, G. D. \& Sánchez, D. (2001). Nutrición y manejo del alimento. Métodos para mejorar la camaronicultura en Centroamérica. M.C. En: Haws, M. C. y Boyd, C. E. (eds). Pp. 65-90. Managua, Nicaragua. Disponible en: http://www.cesasin.com.mx/CentroAmerica/4\%20 Nutrici\%C3\%B3n.pdf

Franco, M. A., Blancheton, J. P., Deviller, G., Charrier, A. \& Le, J. Y. (2004). Effect of fish size and hydraulic regime on particulate organic matter dynamics in a recirculation aquaculture system: elemental carbon and nitrogen approach. Aquaculture, 239(1-4), 179-198. https://doi. org/10.1016/j.aquaculture.2004.05.040

Gómez-Jiménez, S., Espinosa-Plascencia, A., Valenzuela-Villa, F. \& Bermúdez-Almada, M. C. (2008). Oxitetracycline (OTC) accumulation and elimination in hemolymph muscle and hepatopancreas of white shrimp Litopenaeus vannamei following an OTC-feed therapeutic treatment. Aquaculture, 274, 24-29. https://doi.org/10.1016/j. aquaculture.2007.11.017

Gong, H., Jiang, D. H., Lawrence, A., González-Félix, M. \& Pérez-Velázquez, M. (2004). Nuevos avances en el estudio de fosfolípidos nutricionales para camarón. Avances en nutrición acuícola VII. Memorias del VII Simposium Internacional de Nutrición Acuícola. 16-19. Nov. Hermosillo, Sonora, México. pp 329-343. Disponible en: https:/www.uanl.mx/utilerias/nutricion_acuicola/VII/ archivos/18Gong\&Lawrence.pdf

González-Carrillo, H. H., Espinosa-Plascencia, A. \& BermúdezAlmada, M. C. (2010). Desarrollo de una metodología para el control de calidad en la elaboración de alimento con enrofloxacina para camarón de cultivo. VII Congreso del Noroeste y III Nacional de Ciencias Alimentarias y Biotecnología. 10 al 13 de noviembre de 2010. Hermosillo, Sonora. México. pp 1415-1425.

Gutiérrez-Dagnino, A., Luna-González, A., Fierro-Coronado, J. A., Álvarez-Ruiz, P., Flores-Miranda, M. C, MirandaSaucedo, S., Medina-Beltrán, V. \& Escamilla-Montes, R. (2015). Efecto de la inulina y del ácido fúlvico en la supervivencia, crecimiento, sistema inmune y prevalencia de WSSV en Litopenaeus vannamei. Latin American Journal of Aquaculture Research, 43(5), 912-921. https:// doi.org/10.3856/vol43-issue5-fulltext-11

Houglum, J., Larson, R. \& Knutson, A. (1997). Assay of chlortetracycline in animal feeds by liquid chromatography with fluorescence detection. Journal of Association of Official Analytical Chemistry International, 80(5), 961965. https://doi.org/10.1093/jaoac/80.5.961

Lara-Espinoza, C. L., Espinosa-Plascencia, A., RiveraDomínguez, M., Astorga-Cienfuegos, K. R. \& Acedo-Félix, E. (2015). Desarrollo de camarón Litopenaeus vannamei en un sistema de cultivo intensivo con biofloc y nulo recambio de agua. Revista AquaTIC., 43, 1-13. http://www. revistaaquatic.com/ojs/index.php/aquatic/article/view/263

Li, E., Chen, C., Zeng, N., Yu, Z., Xiong, X. \& Chen-Quin, J. G. (2008). Comparison of digestive and antioxidant enzymes 
activities, haemolymph oxyhemocianin contents and hepatopancreas histology of white shrimp, Litopenaeus vannamei at various salinities. Aquaculture, 274(1), 80-86. https://doi.org/10.1016/j.aquaculture.2007.11.001

Li, E., Chen, L., Zheng, C., Chen, X., Yu, N., Lai, Q. \& Quin, J. G. (2007). Growth, body composition, respiration and ambient ammonia nitrogen tolerance of juvenile white shrimp Litopenaeus vannamei, at different salinities. Aquaculture, 265(1-4), 385-390. https://doi.org/10.1016/j. aquaculture.2007.02.018

Lightner, D.V. (1996). A Handbook of shrimp pathology and diagnostic procedures of diseases of cultured penaeid shrimp. World Aquaculture Society, pp 304.

Limsuwan, C. (2005). Cultivo intensivo del camarón blanco: Resumen de visitas y conferencias a camaroneras de Perú. Boletín Nocovita del camarón del mar, Ene-Mar, pp 1-6.

Lunestad, B. T., Hannisdal, R. \& Samuelsen, O. (2015). Safety of medical feed additives in the food chain. Feed and Feeding Practices in Aquaculture. Disponible en: http:// dx.doi.org/10.1016/B978-0-08-100506-4.00010-6.

Ma, R., Wang, Y., Zou, X., Fu, G., Li, C., Fan, P. \& Fang, W. (2019). Pharmacokinetics of oxytetracycline in Pacific white shrimp, Penaeus vannamei, after oral administration of a single-dose and multiple-doses. Aquaculture, 512, 734348. https://doi.org/10.1016/j.aquaculture.2019.734348

Newman, S. G. (2015). Vibrio control in shrimp farming. Global Aquaculture Advocate. 18, 24-25. Disponible en: https://www.aquaculturealliance.org/advocate/vibriocontrol-in-shrimp-farming-part-1/

O'Keefe, T. \& Campabadal, C. A. (2015). Storage and handling of feeds for fish and shrimp. Feed and Feeding Practices in Aquaculture. Disponible en: http://dx.doi.org/10.1016/ B978-0-08-100506-4.00012-X. p 299-313.

Roque, A., Molina-Aja, A., Bolan-Mejia, C. \& Gomez-Gil, B. (2001). In vitro susceptibility to 15 antibiotics of vibrios isolated from penaeid shrimps in Northwestern Mexico. International Journal of Antimicrobial Agents, 17(5), 383-387. https://doi.org/10.1016/s09248579(01)00308-9

Samuelsen, O. B., Lunestad, B. T., Hannisdal, R., Bannister, R., Olsen, S., Tjensvoll, T., Farestveit, E. \& Ervik, A. (2015). Distribution and persistence of the anti sea-lice drug teflubenzuron in wild fauna and sediments around a salmon farm, following a standard treatment. Science Total Environmental, 508, 115-121. https://doi.org/10.1016/j. scitotenv.2014.11.082

Santiago-Hernández, M. L. (2009). Acumulación de Oxitetraciclina (OTC) en camarón de cultivo Litopenaeus vannamei y pruebas de sensibilidad en bacterias tipo Vibrio aisladas de un sistema de cultivo. Tesis de Maestría. Centro de Investigación en Alimentación y Desarrollo, A. C. Hermosillo, Sonora, México. pp. 45-50.

Soto-Rodríguez, S. A., Gómez-Gil, B., Roque, A. \& Lozano, R. (2008). MIC'S de antibióticos de Vibrio spp aislados de L. vannamei cultivado en México. Panorama Acuícola Magazine, Nov-Dic. pp. 53-56.
Tapia-Salazar, M., García-Pérez, O. D., Velásquez-Soto, R. A., Nieto-López, M. G., Villarreal-Cavazos, D., RicqueMarie, D. \& Cruz-Suárez, L. E. (2012). Growth, feed intake, survival, and histological response of White shrimp Litopenaeus vannamei fed diets containing graings naturally contaminated with aflatoxin. Ciencias Marinas, 38(3), 491-504. Disponible en: https://www.redalyc.org/ articulo.oa? $\mathrm{id}=48024401002$

Torres, C. \& Zaragoza, M. (2002). Antibióticos como promotores de crecimiento en animales ¿Vamos por buen camino? Gaceta Sanitaria, 16(2), 09-112. https://doi. org/10.1016/S0213-9111(02)71640-3

Uno, K., Aoki, T., Kleechaya, W., Tanasomwang, V. \& Ruangpan, L. (2006). Pharmacokinetics of oxytetracycline in black tiger shrimp, Penaeus monodon, and the effect of cooking on the residues. Aquaculture, 254, 24-31. https:// doi.org/10.1016/j.aquaculture.2005.10.031

USDA, (1987). Food Safety and Inspection Service. Determining Acceptability of Methods for Regulatory Purpose (2.2.3). Chemistry Laboratory Quality Assurence Handbook. Vol II. United States. Department of Agriculture, Beltsville, MD. USA.

Valverde-Moya, J. A. \& Alfaro-Montoya, J. (2015). Crecimiento compensatorio y producción en las fases de precría, preengorde y engorde comercial del camarón blanco, Litopenaeus vannamei, en Costa Rica. Revista Ciencias Marinas y Costeras, 7, 99-115. https://doi.org/10.15359/ REVMAR.7.7

Venkateswara-Rao, A. (2009). Vibriosis en la acuicultura del camarón. India. Disponible en: http://www.panoramaacuicola.com/articulos y entrevistas/2009/03/23/vibriosis_en_la_acuicultura_del_ camaron.html

Vorbach, B. S., Chandesana, H., Derendorf, H. \& Yanong, R. P. E. (2019). Pharmacokinetics of Oxytetracycline in the Giant Danio (Devario aequipinnatus) following bath immersion. Aquaculture, 498, 12-16. https://doi. org/10.1016/j.aquaculture.2018.08.027

Xu, W. J., Morris, T. C. \& Samocha, T. M. (2016). Effects of $\mathrm{C} / \mathrm{N}$ ratio on biofloc development, water quality, and performance of Litopenaeus vannamei juveniles in a biofloc-based, high-density, zero-exchange, outdoor tank system. Aquaculture, 453, 169-175. https://doi. org/10.1016/j.aquaculture.2015.11.021

Yohenia, C. J. \& Bolaños, N. M. B. (2013). Efecto de dos tipos de dietas: Comercial y experimental cobre el crecimiento de camarones Litopenaeus vannamei en etapa de postlarvas. Universidad Nacional Autónoma de Nicaragua. Facultad de Ciencia y Tecnología. pp. 49-52. http://riul.unanleon. edu.ni:8080/jspui/bitstream/123456789/3107/1/225254. pdf

Zhou, Y., Thirumurugan, R., Wang, Q., Lee, C. M. \& Davis, D. A. (2016). Use of dry hydrolysate from squid and scallop product supplement in plan based practical diets for Pacific white shrimp Litopenaeus vannamei. Aquaculture, 465, 53.59. https://doi.org/10.1016/j.aquaculture.2016.08.028 